\title{
Enhanced expression of SETDB1 possesses prognostic value and promotes cell proliferation, migration and invasion in nasopharyngeal carcinoma
}

\author{
JING HUANG $^{1 *}$, WEIYUAN HUANG ${ }^{2 *}$, MEI LIU ${ }^{2}$, JIANPING ZHU ${ }^{2}$, DANXIAN JIANG ${ }^{1}$, \\ YINGHUAN XIONG ${ }^{3}$, YAN ZHEN ${ }^{4}$, DONGHONG YANG ${ }^{1}$, ZIHONG CHEN $^{1}$, \\ LIJIAO PENG ${ }^{1}$ and ZHONGHUA YU ${ }^{1}$
}

\begin{abstract}
${ }^{1}$ Oncology Center, Affiliated Hospital of Guangdong Medical University, Zhanjiang, Guangdong 524001;
${ }^{2}$ Department of Neurobiology, School of Basic Medical Sciences, Southern Medical University, Guangzhou, Guangdong 510515; ${ }^{3}$ Pathological Diagnosis and Research Center, and ${ }^{4}$ Institute of Respiratory Diseases, Affiliated Hospital of Guangdong Medical University, Zhanjiang, Guangdong 524001, P.R. China
\end{abstract}

Received November 7, 2017; Accepted June 7, 2018

DOI: $10.3892 / o r .2018 .6490$

\begin{abstract}
SETDB1, an H3K9-specific histone methyltransferase, has been described as a repressed transcription marker which triggers tumorigenesis of many types of human cancer. However, there are few studies elucidating the relationship between SETDB1 and nasopharyngeal carcinoma. In the present study, we confirmed that SETDB1 exhibited higher expression levels in nasopharyngeal carcinoma (NPC) tissues and cell lines, compared to these levels in non-tumor tissues and a normal human nasopharyngeal epithelial cell line. Kaplan-Meier analysis showed that higher SETDB1 expression indicated an unfavorable prognosis for NPC patients, making it an independent prognostic factor for NPC in the COX proportional hazards model. In vitro functional studies revealed that upregulation of $S E T D B 1$ expression in CNE1 cells promoted cell proliferation, possibly through cell cycle G1/S phase transition. Moreover, it also enhanced cell migration and invasion ability. Downregulation of SETDBI expression in 5-8F cells resulted in the opposite response. Overall, the findings indicated that increased expression of SETDB1 may predict poor overall survival and the malignant phenotype of NPC.
\end{abstract}

Correspondence to: Dr Lijiao Peng or Professor Zhonghua Yu, Oncology Center, Affiliated Hospital of Guangdong Medical University, Zhanjiang, Guangdong 524001, P.R. China

E-mail: 244348566@qq.com

E-mail: zhonghua_yu@163.com

*Contributed equally

Key words: SETDB1, nasopharyngeal carcinoma, prognosis, tumorigenesis

\section{Introduction}

Nasopharyngeal carcinoma (NPC) is the most prevalent head and neck cancer in south China and east Asia, with the highest annual incidence of more than 20 per 100,000 reported among the Cantonese population $(1,2)$. Unfortunately, most patients are diagnosed at the advanced stage (III-IVb) during their first visit. This is because the primary tumor is commonly located in a silent area, and NPC exhibits high rates of local invasion and distant metastasis $(3,4)$. Despite using chemotherapy combined with intensity-modulated radiotherapy, the outcome for advanced stage patients remains unsatisfactory $(5,6)$. Local recurrence and distant metastasis are two major causes of treatment failure. Therefore, novel biomarkers for early diagnosis and new therapeutic targets are in high demand to aid in the treatment of NPC patients $(7,8)$.

NPC is etiologically associated with genetic and environmental factors, but also with complex pathological processes including squamous metaplasia of nasal mucosa and basal cell dysplasia. It is commonly considered that nasopharyngeal carcinogenesis is a multi-stage and multi-channel process of which the detailed underlying molecular mechanisms remain to be elucidated. SETDB1, a histone H3 lysine 9 (H3K9) methyltransferase, was first identified as a SET (Su(var), Enhancer of zeste, Trithorax) domain-containing protein following an in silico search $(9,10)$. SETDB1 helps regulate the transcriptional repression of euchromatin and plays a central role in the early development of embryonic stem cells by repressing a subset of genes encoding for developmental regulators (11). Moreover, SETDBI is a recognized oncogene in many types of cancers including melanoma (12), lung cancer (13-15), glioma (16), hepatocellular carcinoma (17-20), breast $(21,22)$, urothelial carcinoma (23) and prostate cancer (24). These observations support the hypothesis that aberrant histone methylation leads to the activation or repression of critical genes during tumorigenesis. However, little is known concerning the role of SETDB1 in nasopharyngeal carcinogenesis. In the present study, we first determined the 
expression of SETDB1 in NPC and further explored its potential role in NPC progression.

\section{Materials and methods}

Tissue specimens. A tissue microarray block containing 152 NPC samples and their clinic-pathological information was purchased from Shanghai Outdo Biotech Co., Ltd. (Shanghai, China). Paraffin-embedded nasopharynx mucosal tissues, between January 2006 and December 2008, were collected for control study from the Department of Pathology at the Affiliated Hospital of Guangdong Medical University. None of the patients received radiotherapy or chemotherapy prior to biopsy. Informed consent was obtained in all cases, and protocols were approved by the Institutional Ethics Committee of the Affiliated Hospital of Guanddong Medical University.

Immunohistochemical staining. Using the EnVision Detection System, immunohistochemical staining assays were performed on tissue slides according to the manufacturer's protocol (Dako). In brief, slides were incubated with a SETDB1 primary antibody (1:100 dilution; cat. no. HPA018142; Sigma-Aldrich, St. Louis, MO, USA) overnight at $4^{\circ} \mathrm{C}$ and washed with phosphate-buffered saline (PBS). Next, the slides were treated with horseradish peroxidase-conjugated secondary antibodies (ChemMate ${ }^{\mathrm{TM}}$ EnVision+ HRP; cat. no. GK500705; Gene Tech Co., Shanghai, China) before staining with diaminobenzidine and counterstaining with hematoxylin. Negative controls were routinely performed. All of the staining was evaluated and scored by two independent pathologists. The score was a sum of the percentage of positive-stained cells $(0,0 \% ; 1,1-10 \%$; $2,11-50 \% ; 3,56-75 \%$; and $4,76-100 \%)$ and the mean intensity of the staining ( 0 , no staining; 1 , weak staining; 2 , moderate staining; and 3, strong staining). A score of $\leq 4$ was considered as weak or negative SETDB1 protein expression, whereas a higher score was considered as overexpression.

Cell lines. The human NPC cell lines HONE1, SUNE1, CNE1, CNE2, 5-8F and 6-10B were obtained from the Cancer Institute, Southern Medical University (Guangzhou, China). These cell lines were maintained in RPMI-1640 medium (Gibco; Thermo Fisher Scientific, Inc., Waltham, MA, USA) supplemented with $10 \%$ heat-inactivated fetal bovine serum (FBS) and $100 \mathrm{U} \mathrm{ml}^{-1}$ of penicillin and streptomycin (Gibco; Thermo Fisher Scientific, Inc.) at $37^{\circ} \mathrm{C}$ in a humidified atmosphere containing 5\% $\mathrm{CO}_{2}$. NP69 (immortalized normal human nasopharyngeal epithelial cell line) was purchased from the Department of Physiology, Jinan University (Guangzhou, China), and grown in defined keratinocyte-serum-free medium supplemented with epidermal growth factor (EGF; Invitrogen; Thermo Fisher Scientific, Inc.).

$R T-q P C R$. Total RNA was extracted using TRIzol reagent (Invitrogen; Thermo Fisher Scientific, Inc.). Reverse transcription was performed with $1 \mu \mathrm{g}$ gDNA-Eraser-treated total RNA template, using Oligo dT and reverse transcriptase (Takara Bio, Inc., Otsu, Japan), according to the supplier's instructions. Quantitative PCR was performed with SYBR Premix Ex
Taq (Takara Bio) using an Applied Biosystems 7500 Fast Real-Time PCR System (Life Technologies; Thermo Fisher Scientific, Inc.). PCR primers included: SETDB1 sense (5'-AAGACGTACTCAGGCCATGTCC-3') and SETDB1 antisense (5'-GACCCAAATGTCGCAGTCAG-3'); $\beta$-actin sense (5'-TAAGAAGCTGCTGTGCTACG-3') and $\beta$-actin antisense (5'-GACTCGTCATACTCCTGCTT-3'). SETDB1 was amplified by 35 cycles at $94^{\circ} \mathrm{C}$ for $15 \mathrm{sec}, 58^{\circ} \mathrm{C}$ for $30 \mathrm{sec}$, and $68^{\circ} \mathrm{C}$ for $2 \mathrm{~min}$ in order, which was followed by a 10 -min extension at $68^{\circ} \mathrm{C}$. The $\Delta \Delta$ method was used to determine the relative levels of mRNA expression between the experimental samples and controls as previously described (25). The fold change in gene expression was calculated as $2^{-\Delta \Delta \mathrm{Cq}}$. PCR products were electrophoresed on $1.2 \%$ agarose gel containing ethidium bromide and visualized by UV-induced fluorescence.

Western blotting. Cell pellets were lysed on ice in RIPA buffer (1X PBS, 1\% NP-40, 0.1\% SDS, 5 mM EDTA, 0.5\% sodium deoxycholate and $1 \mathrm{mM}$ sodium orthovanadate) with protease inhibitors. Protein extracts were quantified using a bicinchoninic acid (BCA) protein assay (Nanjing KeyGen Biotech, Co., Ltd., Nanjing, China), separated by $6 \%$ SDS-PAGE and analyzed by immunoblotting using primary antibodies specific for human SETDB1 (1:800 dilution; cat. no. ab107225; Abcam, Cambridge, UK), human $\beta$-actin (1:1,000 dilution; cat. no. 4970; Cell Signaling Technology, Inc., Danvers, MA, USA) and affinity-purified goat anti-rabbit/mouse secondary antibody (1:2,000 dilution; cat. nos. 7074 and 7076; Cell Signaling Technology, Inc.).

Stable transfection regulates SETDBI expression. The $S E T D B 1$ full coding sequence was cloned into the pGLV5 lentiviral expression vector. Verified SETDB1 targeting short hairpin RNA (shRNA) sequences (GCATGCGAATTCTGG GCAAGA) were cloned into the pGLV3 vectors. Non-target control shRNA (TTCTCCGAACGTGTCACGTTTC) was included as a negative control. The regenerated plasmid and its negative control were respectively transfected into 293FT cells using Lipofectamine 2000 (Invitrogen; Thermo Fisher Scientific, Inc.) following the manufacturer's instructions. The viral supernatants were harvested, filtered, and the virus titer was determined. Lentiviruses that contained the SETDBI shRNA and the negative control vector were stably infected into the NPC cell line $5-8 \mathrm{~F}$, while those containing the exogenous $S E T D B 1$ coding sequence were infected into the $\mathrm{CNE} 1$ cell line. Flow cytometry assays were used to sort stable integrants. Both RT-PCR and western blot analysis confirmed SETDB1 expression.

Cell viability assay. The target cells were seeded in 96-well plates at a density of 100 cells/well in $0.1 \mathrm{ml}$ media. Following an overnight incubation, $10 \mathrm{ml}$ of Cell Counting Kit 8 (CCK-8; Dojundo Laboratories, Kumamoto, Japan) was mixed with $100 \mathrm{ml}$ of RPMI-1640 (Gibco; Thermo Fisher Scientific, Inc.) and added to each well. The mixture was incubated at $37^{\circ} \mathrm{C}$ for $1.5 \mathrm{~h}$ before measuring the absorbance at $450 \mathrm{~nm}$ over the next $96 \mathrm{~h}$. All experiments were performed in triplicate.

Cell cycle analysis. The cells cycle was analyzed as previously described (26). 
A

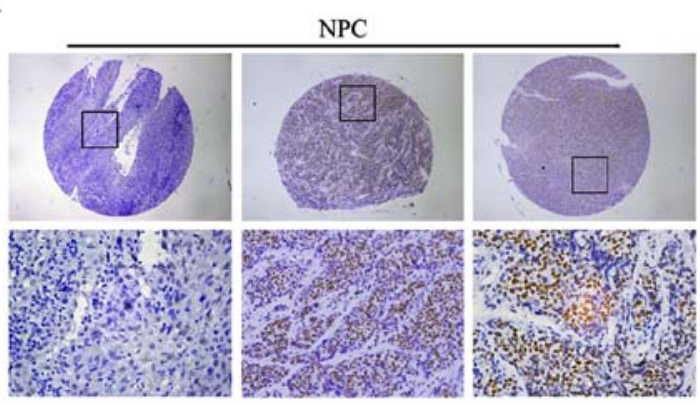

C

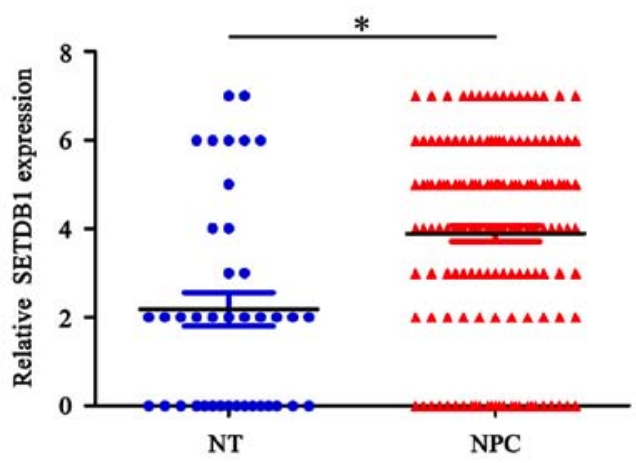

B

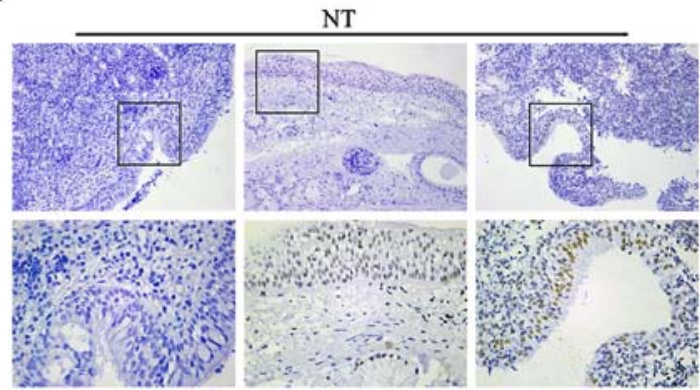

D

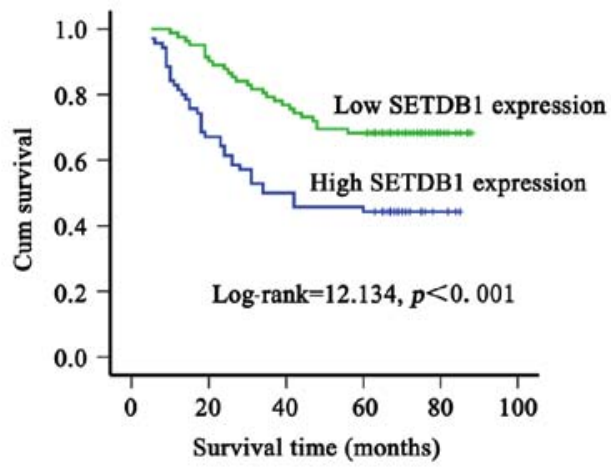

Figure 1. Expression analysis of SETDB1 protein in tissues by immunohistochemistry and Kaplan-Meier plot of overall survival rate in patients with NPC. (A) Negative and positive expression of SETDB1 in representative NPC samples. Original magnifications, x40 (upper panel), x400 (lower panel). (B) SETDB1 staining of nasopharynx mucosal tissues (labeled NT). Original magnifications, $\mathrm{x} 100$ (upper panel), $\mathrm{x} 400$ (lower panel). (C) The staining score of immunohistochemical for NT $(n=39)$ and NPC tissues $(n=152)$, respectively. (D) Kaplan-Meier analysis of overall survival duration in all patients according to SETDB1 expression. ${ }^{*} \mathrm{P}<0.05$.

Transwell assays. Cell migration and invasion ability was assessed in 24-well Transwell inserts $(8.0-\mu \mathrm{m}$ pore size; Corning Inc., Corning, NY, USA). For the migration assay, $200 \mu \mathrm{l}$ of serum-free medium containing $1 \times 10^{5}$ target cells was added to the top chambers, while the lower chambers were filled with $500 \mu 1$ complete RPMI-1640 medium containing $10 \%$ FBS. Minor changes were implemented for the cell invasion assay; the Transwell inserts were pre-coated with diluted Matrigel (Sigma-Aldrich; Merck KGaA) and 3x10 cells were added to the top chambers. After 18-24 h of incubation, the cells that had migrated or invaded to the undersurface of the membrane were fixed in $100 \%$ methanol and stained with $0.1 \%$ crystal violet. Cells in five random fields were visualized and counted under a microscope (Olympus CX41; Olympus Corp., Tokyo, Japan).

Statistical analysis. SPSS 13.0 software (SPSS, Inc., Chicago, IL, USA) was used for the statistical analysis. Survival curves were plotted following the Kaplan-Meier method and compared using the log-rank test. The significance of various variables for survival was analyzed by the Cox proportional hazards model (Enter model). The significance of SETDB1 expression and the clinic pathological characteristics was evaluated by the $\chi^{2}$ test. Differences between groups were analyzed by one-way analysis of variance with Tukey's post hoc test. Multiple-factors repetitive measurement was performed by variance analysis. $\mathrm{P}<0.05$ was considered to indicate a statistically significant result.

\section{Results}

SETDB1 is frequently amplified in human NPC. To explore the correlation of SETDB1 expression with human NPC, we detected SETDB1 protein expression in 152 paraffin-embedded samples. As shown in Fig. 1A, SETDB1 showed positive nuclear staining in NPC. One hundred and twenty-six out of $152(82.9 \%)$ patients exhibited SETDB1 amplification. Overexpression of SETDB1 protein was detected in 70 of the $126(55.6 \%)$ NPC tissues, as compared to only 8 of 39 (20.51\%) nasopharynx mucosal tissues (Fig. 1B and C). The overexpression of SETDB1 protein was significantly different between NPC and non-tumor samples $\left(\chi^{2}=5.177, \mathrm{P}=0.023\right)$.

Overexpression of SETDB1 was indicative of poor survival for NPC patients. To investigate the prognostic value of SETDB1 for NPC, we compared the overall survival of patients with high and low SETDB1 protein expression. Kaplan-Meier analysis indicated that the median survival of high SETDB1-expressing patients was 49.1 and 69.6 months for low SETDB1-expressing patients. Overexpression of SETDB1 was significantly correlated with a poorer 5-year survival rate of NPC patients $(\mathrm{P}=0.001$, hazard ratio=0.442). Kaplan-Meier survival curves were also significantly different for the low and high SETDB1 expression patients $(\mathrm{P}<0.001$, log-rank test) (Fig. 1D).

Correlation between SETDB1 expression and clinicopathological parameters. To determine whether SETDB1 expression 
Table I. Correlation between the clinicopathological variables and the expression of SETDB1 protein.

\begin{tabular}{|c|c|c|c|c|c|}
\hline \multirow[b]{2}{*}{ Characteristics } & \multirow[b]{2}{*}{$\mathrm{n}$} & \multicolumn{2}{|c|}{ SETDB1 expression } & \multirow[b]{2}{*}{$\chi^{2}$} & \multirow[b]{2}{*}{ P-value } \\
\hline & & Low & High & & \\
\hline All cases & 152 & 82 & 70 & & \\
\hline Sex & & & & 0.046 & 0.831 \\
\hline Male & 112 & 61 & 51 & & \\
\hline Female & 40 & 21 & 19 & & \\
\hline Age (years) & & & & 0.062 & 0.803 \\
\hline$<50$ & 82 & 45 & 37 & & \\
\hline$\geq 50$ & 70 & 37 & 33 & & \\
\hline $\mathrm{T}$ classification & & & & 5.490 & 0.139 \\
\hline T0-1 & 12 & 9 & 3 & & \\
\hline $\mathrm{T} 2$ & 63 & 32 & 31 & & \\
\hline $\mathrm{T} 3$ & 36 & 23 & 13 & & \\
\hline $\mathrm{T} 4$ & 41 & 18 & 23 & & \\
\hline $\mathrm{N}$ classification & & & & 8.623 & 0.035 \\
\hline N0 & 47 & 27 & 20 & & \\
\hline N1 & 77 & 41 & 35 & & \\
\hline $\mathrm{N} 2$ & 22 & 13 & 9 & & \\
\hline N3 & 6 & 0 & 7 & & \\
\hline Distant metastasis & & & & 2.398 & 0.121 \\
\hline Yes & 5 & 1 & 4 & & \\
\hline No & 147 & 81 & 66 & & \\
\hline Clinical stage & & & & 0.033 & 0.855 \\
\hline I-II & 62 & 34 & 28 & & \\
\hline III-IV & 90 & 48 & 42 & & \\
\hline
\end{tabular}

Bold print indicates significant difference at $\mathrm{P}<0.05$.

could act as an independent prognostic factor for NPC, univariate and multivariate analyses were applied. Results indicated that SETDB1 protein expression was significantly related to overall survival and was an independent prognostic factor in NPC patients (Table II). The relationship between the SETDB1 expression and the clinicopathological characteristics was also examined. As summarized in Table I, no significant correlations were found between SETDB1 expression and any of the assessed clincopathological variables, with the exception of $\mathrm{N}$ classification $\left(\mathrm{P}=0.035, \chi^{2}=8.623\right)$.

Expression of SETDB1 in NPC cell lines. To detect the SETDB1 expression patterns in NPC cell lines, RT-PCR and western blot analyses were performed. All six human NPC cell lines exhibited higher SETDB1 mRNA expression levels compared to the immortalized normal human nasopharyngeal epithelial cell line NP69 (Fig. 2). Western blot analysis confirmed that SETDB1 protein could be detected in all NPC cell lines but not in NP69 cells. Taken together the data suggest a potential role for SETDB1 in NPC tumorigenesis.

Alteration of SETDB1 expression affects the proliferation ability of NPC cells in vitro. To explore the possible impact
A

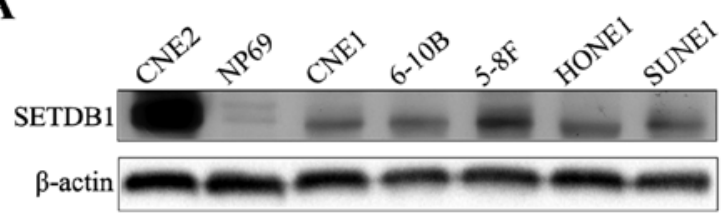

B

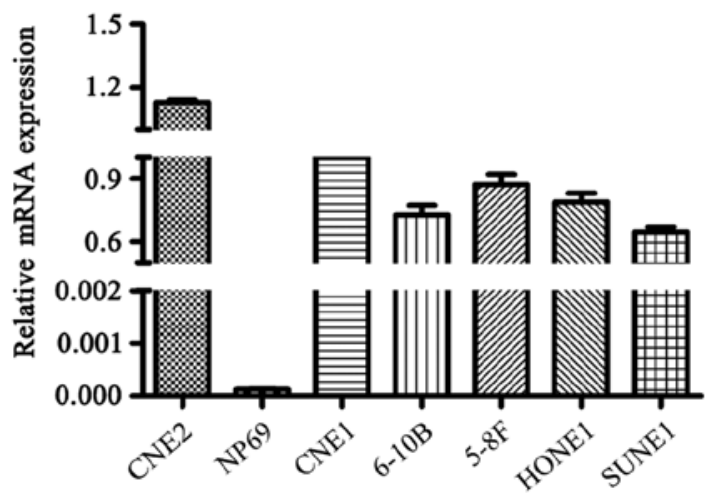

Figure 2. Expression pattern of SETDB1 in NPC cell lines and normal human nasopharyngeal epithelial cell line NP69 was analyzed by (A) western blot analysis and (B) RT-PCR. 
Table II. Summary of overall survival analysis by univariate and multivariate COX regression analyses.

\begin{tabular}{|c|c|c|c|c|c|c|}
\hline \multirow[b]{2}{*}{ Parameters } & \multicolumn{3}{|c|}{ Univariate analysis } & \multicolumn{3}{|c|}{ Multivariate analysis } \\
\hline & P-value & $\mathrm{HR}$ & $95 \%$ CI & P-value & HR & $95 \% \mathrm{CI}$ \\
\hline \multicolumn{7}{|l|}{ Age (years) } \\
\hline$\geq 50$ vs. $<50$ & 0.083 & 1.539 & $0.945-2.507$ & & & \\
\hline \multicolumn{7}{|l|}{ Sex } \\
\hline Male vs. female & 0.006 & 0.376 & $0.186-0.760$ & 0.070 & 1.946 & $0.947-4.001$ \\
\hline \multicolumn{7}{|l|}{$\mathrm{T}$ classification } \\
\hline T0-2 vs. T3-4 & 0.006 & 0.489 & $0.294-0.814$ & 0.221 & 0.640 & $0.314-1.308$ \\
\hline \multicolumn{7}{|l|}{$\mathrm{N}$ classification } \\
\hline N0 vs. N1-3 & 0.037 & 0.532 & $0.294-0.961$ & 0.175 & 1.531 & $0.828-2.833$ \\
\hline \multicolumn{7}{|l|}{ M classification } \\
\hline N0 vs. M1 & 0.000 & 0.116 & $0.045-0.302$ & 0.001 & 5.606 & $2.086-15.064$ \\
\hline \multicolumn{7}{|l|}{ Clinical stage } \\
\hline I-II vs. III-IV & 0.000 & 0.301 & $0.166-0.544$ & 0.002 & 3.900 & $1.676-9.077$ \\
\hline \multicolumn{7}{|l|}{ SETDB1 expression } \\
\hline High vs. low & 0.001 & 0.442 & $0.269-0.727$ & 0.001 & 0.438 & $0.264-0.728$ \\
\hline
\end{tabular}

Bold print indicates $\mathrm{P}<0.05$. HR, hazard ratio; $\mathrm{CI}$, confidence interval.

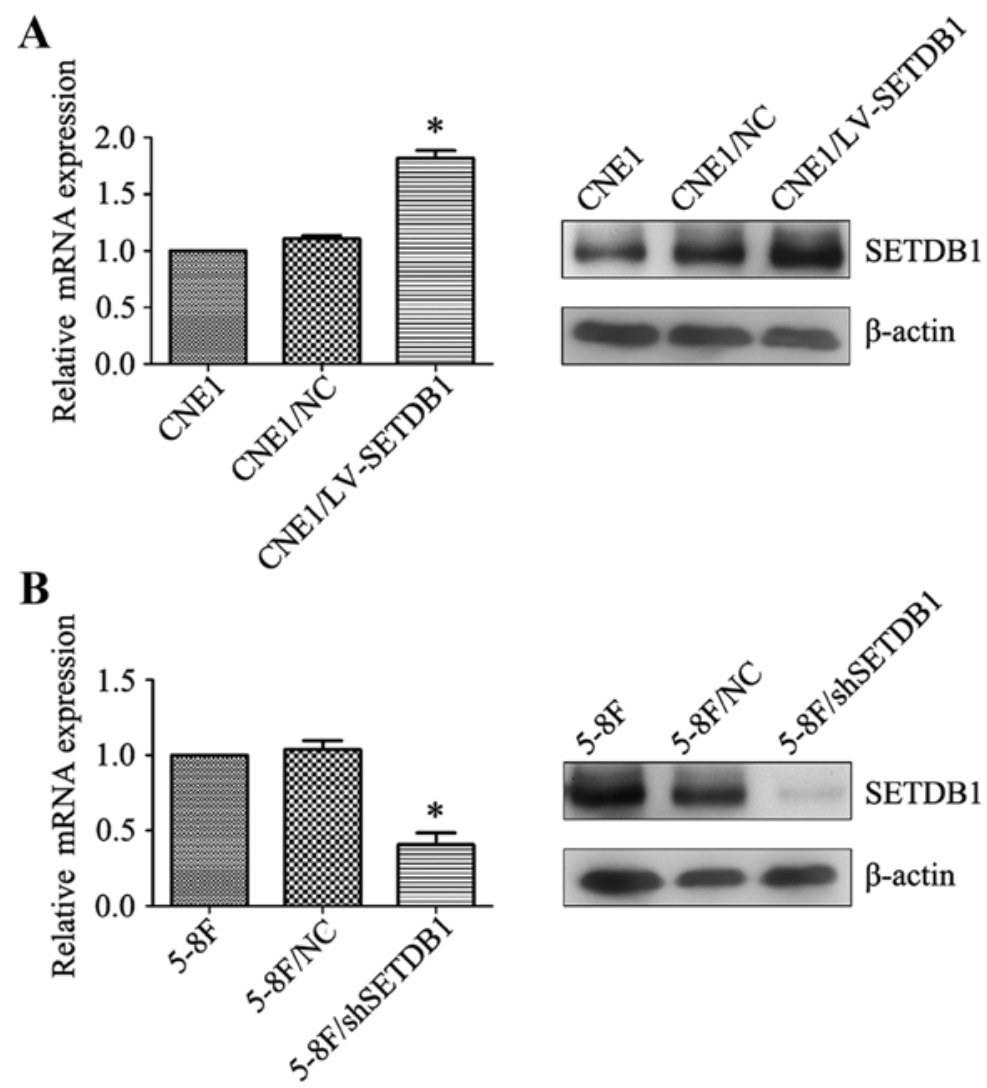

Figure 3. Detection of SETDB1 expression on mRNA and protein levels in transfected cell lines by qRT-PCR and western blot analysis. (A) SETDB1 $\mathrm{mRNA}$ /protein expression levels in CNE1 cells transfected with LV-SETDB1 were higher than controls. (B) Both SETDB1 mRNA and protein were significantly reduced in $5-8 \mathrm{~F}$ cells transfected with shSETDB1. ${ }^{*} \mathrm{P}<0.05$ compared with both the parental and $\mathrm{NC}$ groups.

of altered $S E T D B 1$ expression on the biological behavior of NPC, two cell lines with either SETDB1 knockdown (5-8F/sh-SETDB1) or overexpression (CNE1/LV-SETDB1) were constructed. Alteration of SETDB1 mRNA and protein expression of these two stable cell lines was confirmed by RT-PCR and western blot analysis (Fig. 3). Cell proliferation 
A
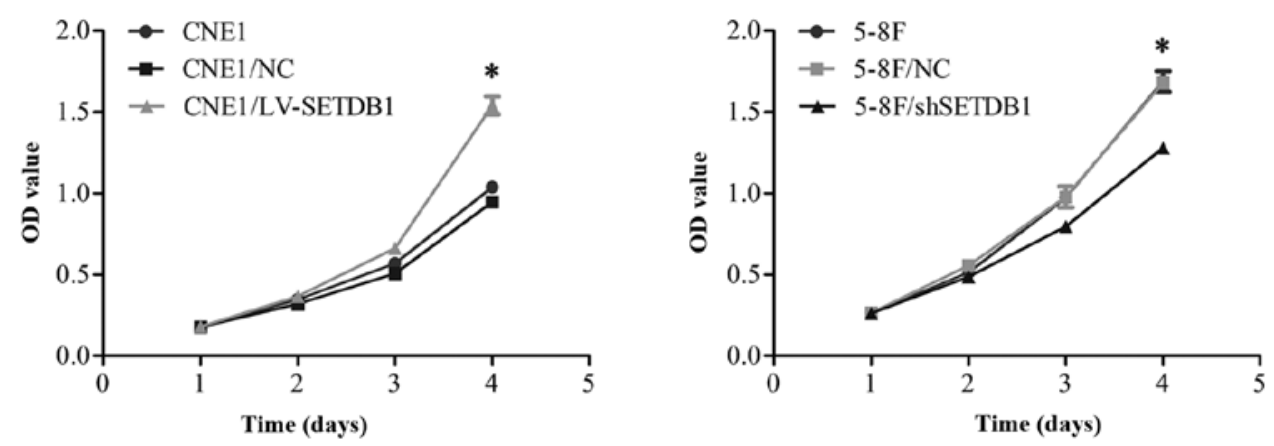

B
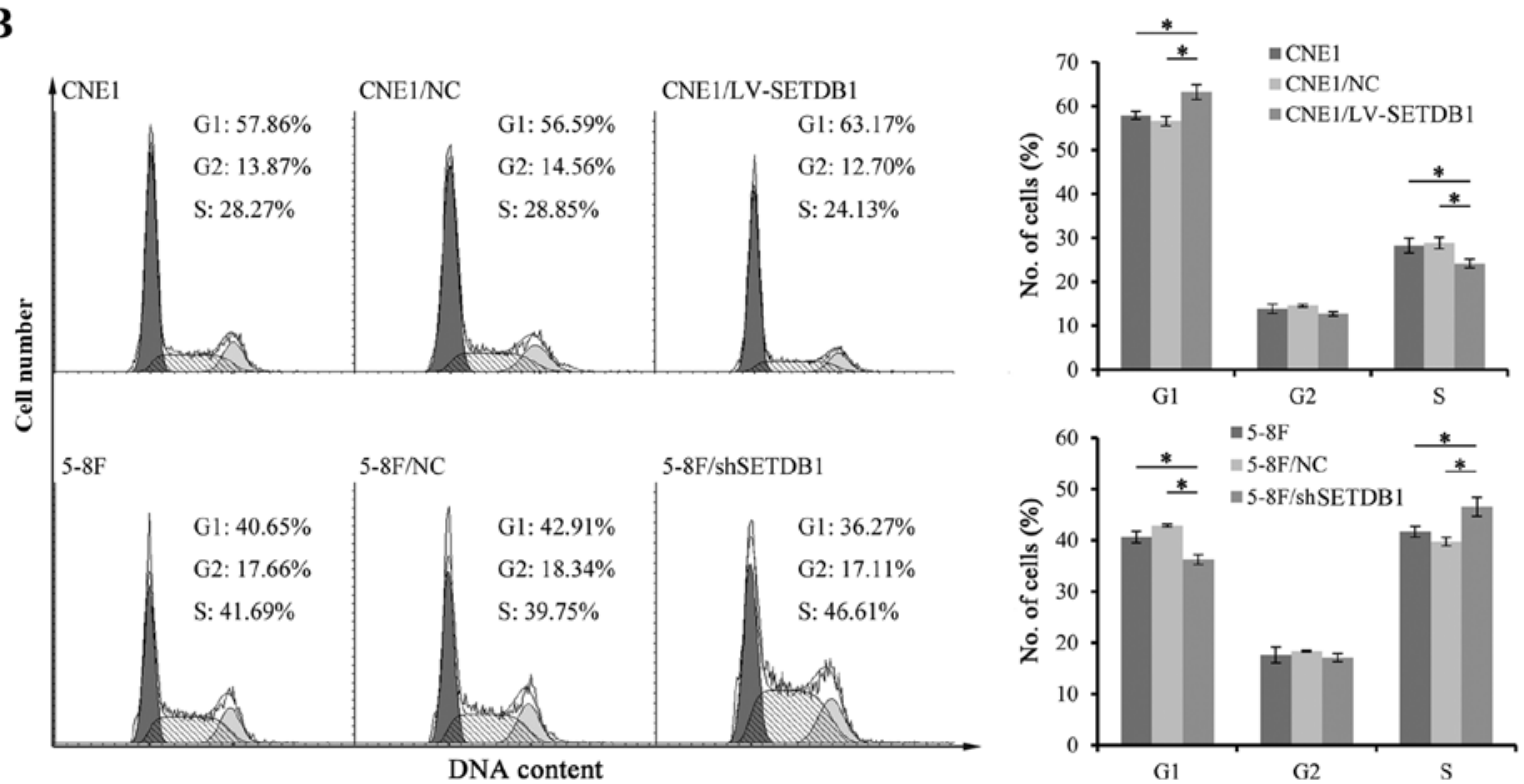

Figure 4. Effect of SETDB1 on cell proliferation and cell cycle distribution of the CNE1 and 5-8F cells following transfection. (A) CCK-8 assay was used to investigate the proliferation ability of NPC cells after SETDB1 was knocked down or upregulated. " $\mathrm{P}<0.001$. (B) Flow cytometric analysis was performed to detect the cell cycle distribution of the different cells. ${ }^{*} \mathrm{P}<0.05$.

was analyzed using CCK-8. Results showed that parental wild-type (WT) CNE1 cells had a similar growth rate to negative controls over a 4 day observation period. On day 4, the growth rate of CNE1/LV-SETDB1 had become significantly more rapid than that of the WT and negative control cell lines (Fig. 4A). Consistent with these results, flow cytometric analysis showed an increased number of cells in the G1 phase and a decreased cell percentage in the S phase of CNE1 cells with increased SETDB1 expression (Fig. 4B). As expected, contrasting results were observed with the $5-8 \mathrm{~F}$ cell line with knocked down SETDB1 expression. Together, the data imply that SETDB1 may play a crucial role in the regulation of NPC cell proliferation.

Alteration of SETDB1 expression affects migration and invasion ability of NPC cells in vitro. We next focused on detecting whether SETDB1 affects cell migration and invasion ability of NPC cells in vitro. The effect of SETDB1 overexpression or knockdown on cell migration capacity was tested with a Transwell assay. As shown in Fig. 5A, cell migration increased by nearly $100 \%$ in the SETDBI overexpression group compared with the WT and negative control cells. Accordingly, cell migration was significantly decreased in the
SETDB1-knockdown cells. Using a Matrigel invasion assay, we observed that the number of cells able to penetrate the Matrigel was 2-fold higher in CNE1/LV-SETDB1 cells than that noted in the controls. In contrast, the invasion ability of 5-8F/sh-SETDB1 cells exhibiting stable SETDB1 knockdown was $<0.5$-fold vs. the controls (Fig. 5B). The data showed that $S E T D B 1$ overexpression or knockdown could respectively promote or attenuate the migration and invasion of NPC cells in vitro. These findings indicated that the migration and invasion ability of NPC cells could be correlated with the SETDBI expression.

\section{Discussion}

NPC is a malignant tumor derived from nasopharyngeal epithelial cells. It is widely accepted that NPC is a complicated disease associated with multiple factors including genetics (27,28), Epstein-Barr virus infection (29-31) and the environment (32). Thus far, researchers have mainly focused on improving our understanding of NPC pathogenesis (33-36). However, we still need further insight into the underlying molecular genetics of NPC, which would enable future tailored patient prognostication and treatment strategies. SETDB1, a 
A
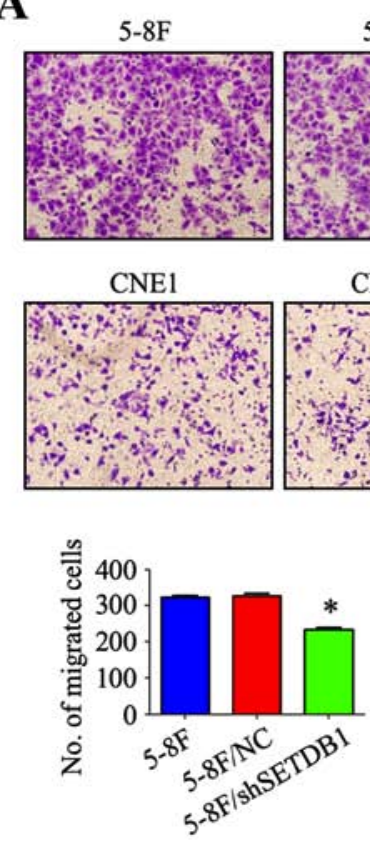

5-8F/NC

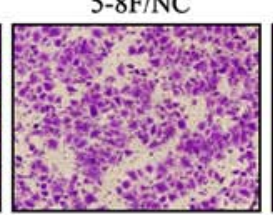

CNE1-NC

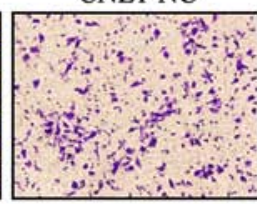

5-8F/shSETDB1

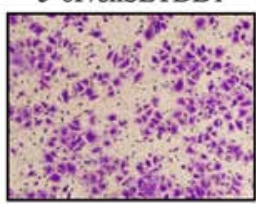

CNE1/LV-SETDB1

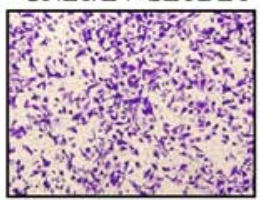

B

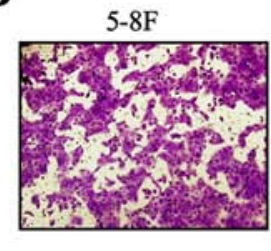

CNE1
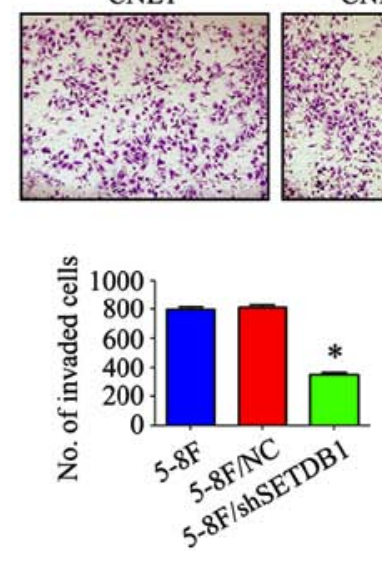

$5-8 \mathrm{~F} / \mathrm{NC}$

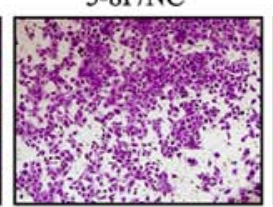

CNE1/NC

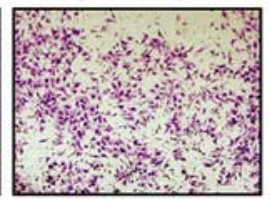

5-8F/shSETDB1

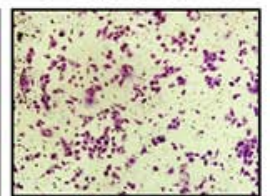

CNE1/LV-SETDB1

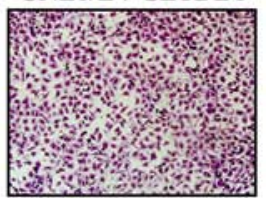

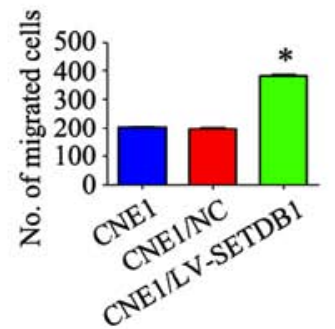

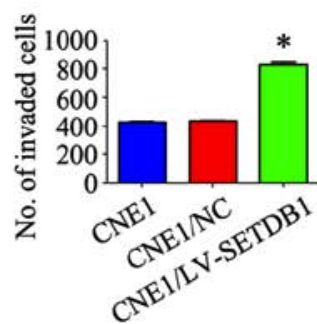

Figure 5. Transwell assay showing that aberrant expression of SETDB1 in NPC cells affects their migration (A) and invasion (B) abilities. ${ }^{*}<0.05$.

histone lysine methyltransferase, plays an important role in methylation and gene silencing (37,38). Recent studies indicate that SETDB1 is markedly increased in various types of human cancer, including melanoma, lung cancer, hepatocellular carcinoma, breast, urothelial carcinoma and prostate cancer, contributing to enhanced tumor growth and metastasis. Hence, SETDB1 is a promising therapeutic target for cancer (39-41). This study furthered the understanding of SETDB1 and explored its potential role in tumorigenesis and NPC.

To the best of our knowledge, the study presented herein is the first to examine SETDB1 expression by immunohistochemical staining of well-annotated NPC samples. We observed that SETDB1 is frequently amplified in human NPC tissues, with 126 out of 152 NPC patients exhibiting SETDB1 amplification. The rate of overexpression of SETDB1 protein in tumor samples was higher than that noted in nasopharynx mucosal tissues (55.6 vs. 20.51\%, $\mathrm{P}<0.05)$. Kaplan-Meier survival analysis revealed a significant correlation between SETDB1 expression and patient survival where the higher the expression of SETDB1, the shorter the survival time was for NPC patients. This result is in agreement with previous observations of high SETDB1 expression levels in various cancer tissues, which demonstrated that SETDB1 overexpression can be linked to a poor prognosis of NPC patients. Furthermore, the association between SETDB1 expression and NPC clinicopathologic variables was also examined. Overexpression of SETDB1 was found to be significantly associated with $\mathrm{N}$ classification. Consistent with its expression pattern in tissues, SETDB1 expression was higher in 6 different NPC cell lines compared with the normal human nasopharyngeal epithelial cell line NP69. These results confirmed the clinical significance of SETDB1 as a biomarker for NPC prognosis and the close relationship between SETDB1 expression and tumorigenesis.
The role of SETDB1 in promoting tumor progression has been investigated in a previous study. A study by Spyropoulou et al (16) demonstrated that SETDB1 knockdown by siRNA considerably reduced proliferation, migration and clonogenic ability, and induced apoptosis in glioma cell lines. Olcina et al (42) furthermore reported that increased H3K9 methylation by SETDB1 is observed along with APAK (ATM and p53-associated KZNF protein) repression in hypoxic conditions, which was speculated to improve prognosis in colorectal cancer cases. According to Zhang et al (22) miR-7 inhibited cancer metastasis and inversed epithelial-mesenchymal transition of human breast cancer stem cell via directly diminishing oncogenic SETDB1 expression. Additionally, Wong et al (43) revealed that SETDB1 expression was markedly increased in liver cancer patients, due to activating factors at the chromosomal, transcriptional and post-transcriptional levels. Our preliminary work identified a protein-protein interaction between SETDB1 and T cell lymphoma invasion and metastasis 1 (Tiam1) in hepatocellular carcinoma (HCC) according to yeast two-hybrid, which was confirmed by GST pull down and crosslink immunoprecipitation assays. We also revealed that the expression of SETDB1 was frequently upregulated in HCC tissues and that this was positively correlated with Tiam1, resulting in HCC progression (data not shown). Riviere and colleagues (44) showed that HBx relieves chromatin-mediated transcriptional repression of hepatitis $\mathrm{B}$ viral cccDNA involving SETDB1 histone methyltransferase. Thus, SETDB1 was considered to be a new promising target in HCC therapy. Moreover, SETDB1 is predicted to be involved in dedifferentiation such as the development of induced pluripotent stem cells or in tumorigenesis which involves conversion of somatic cells to cells with a more plastic phenotype $(11,45)$.

There is increasing evidence that supports the role of SETDB1 in inducing invasion and metastasis in a wide range 
of cancers. There are, however, no reports on SETDB1 and $\mathrm{NPC}$, hence we used the retroviral gene transfer method to alter the expression of endogenous SETDB1 in NPC cells. The $5-8 \mathrm{~F}$, a high metastatic potential NPC cell line, was genetically recombined to knock down endogenous $S E T D B 1$, while a CNE1 cell line was used to overexpress SETDB1. By knocking down SETDB1 expression we observed suppression of cell proliferation, migration and invasion in vitro, and vice versa for $S E T D B 1$ overexpression. Our data were therefore in agreement with previous findings for SETDB1 in other cancers and confirmed its important role in promoting tumorigenesis.

In summary, the study presented herein identified an association between SETDBI expression and NPC. In order to improve our understanding of the mechanism of carcinogenesis and tumor progression in patients with NPC, future research will require a larger set of samples and samples of different pathological types as well as molecular, cellular and animal model studies. As a potential biomarker for NPC it is imperative to further analyze the predictive power of SETDB1 expression in future studies.

\section{Acknowledgements}

Not applicable.

\section{Funding}

The present study was supported by the National Science Fund of China (grant no. 81502532), the Nature Science Fund of Guangdong Province of China (grant no. 2014A030310101), the Innovation and Strengthening School Project of Higher Education in Guangdong Province (grant no. 2014KQNCX0 95 ) and the Guangdong medical university research foundation (grant no. Z2014004).

\section{Availability of data and materials}

The dataset generated or analyzed during this study are available from the corresponding author on reasonable request.

\section{Authors' contributions}

JH and WYH conceived and designed the study, analyzed and interpreted the data and drafted the manuscript. ML and JPZ jointly performed the experiments, DXJ, DHY and YZ contributed to the clinical sample collection. YHX and ZHC contributed to pathological analysis. LJP and ZHY reviewed the manuscript and supervised the study. All authors read and approved the manuscript and agree to be accountable for all aspects of the research in ensuring that the accuracy or integrity of any part of the work are appropriately investigated and resolved.

\section{Ethics approval and consent to participate}

Ethical approval for this study was obtained from the Ethics Committee of Taizhou Hospital of Zhejiang Province and the Affiliated Hospital of Guangdong Medical University. This study does not contain any studies with animals performed by any of the authors. Written informed consent was obtained from each individual participant.

\section{Patient consent for publication}

Not applicable.

\section{Competing interests}

The authors state that they have no competing interests.

\section{References}

1. Torre LA, Bray F, Siegel RL, Ferlay J, Lortet-Tieulent J and Jemal A: Global cancer statistics, 2012. CA Cancer J Clin 65: 87-108, 2015

2. Venugopal R, Bavle RM, Konda P, Muniswamappa S and Makarla S: Familial cancers of head and neck region. J Clin Diagn Res 11: ZE01-ZE06, 2017.

3. Cao SM, Simons MJ and Qian CN: The prevalence and prevention of nasopharyngeal carcinoma in China. Chin J Cancer 30: 114-119, 2011.

4. Lee AW, Ma BB, Ng WT and Chan AT: Management of nasopharyngeal carcinoma: Current practice and future perspective. J Clin Oncol 33: 3356-3364, 2015.

5. Zhang MX, Li J, Shen GP, Zou X, Xu JJ, Jiang R, You R, Hua YJ, Sun Y, Ma J, et al: Intensity-modulated radiotherapy prolongs the survival of patients with nasopharyngeal carcinoma compared with conventional two-dimensional radiotherapy: A 10-year experience with a large cohort and long follow-up. Eur J Cancer 51: 2587-2595, 2015.

6. Ruuskanen M, Grenman R, Leivo I, Vahlberg T, Mäkitie A, Saarilahti K, Wigren T, Korpela M, Voutilainen L, Koivunen $\mathrm{P}$, et al: Outcome of nasopharyngeal carcinoma in Finland: A nationwide study. Acta Oncol 57: 251-256, 2018.

7. Chen X, Zhu X, Liang Z, Li L, Qu S, Chen K and Pan X: Long-term outcomes of neoadjuvant chemotherapy followed by concurrent chemoradiotherapy (CCRT) vs CCRT alone for nasopharyngeal carcinoma in the era of intensity-modulated radiation therapy using propensity score matching method. OncoTargets Ther 10: 2909-2921, 2017.

8. Ribassin-Majed L, Marguet S, Lee AWM, Ng WT, Ma J, Chan ATC, Huang PY, Zhu G, Chua DTT, Chen Y, et al: What is the best treatment of locally advanced nasopharyngeal carcinoma? An individual patient data network meta-analysis. J Clin Oncol 35: 498-505, 2017.

9. Harte PJ, Wu W, Carrasquillo MM and Matera AG: Assignment of a novel bifurcated SET domain gene, SETDB1, to human chromosome band 1q21 by in situ hybridization and radiation hybrids. Cytogenet Cell Genet 84: 83-86, 1999.

10. Park I, Hwang YJ, Kim T, Viswanath ANI, Londhe AM, Jung SY, Sim KM, Min SJ, Lee JE, Seong J, et al: In silico probing and biological evaluation of SETDB1/ESET-targeted novel compounds that reduce tri-methylated histone H3K9 (H3K9me3) level. J Comput Aided Mol Des 31: 877-889, 2017.

11. Kang YK: SETDB1 in early embryos and embryonic stem cells. Curr Issues Mol Biol 17: 1-10, 2015.

12. Ceol CJ, Houvras Y, Jane-Valbuena J, Bilodeau S, Orlando DA, Battisti V, Fritsch L, Lin WM, Hollmann TJ, Ferré F, et al: The histone methyltransferase SETDB1 is recurrently amplified in melanoma and accelerates its onset. Nature 471: 513-517, 2011.

13. Wu PC, Lu JW, Yang JY, Lin IH, Ou DL, Lin YH, Chou KH, Huang WF, Wang WP, Huang YL, et al: H3K9 histone methyltransferase, KMT1E/SETDB1, cooperates with the SMAD2/3 pathway to suppress lung cancer metastasis. Cancer Res 74: 7333-7343, 2014.

14. Lafuente-Sanchis A, Zúñiga Á, Galbis JM, Cremades A, Estors M, Martínez-Hernández NJ and Carretero J: Prognostic value of ERCC1, RRM1, BRCA1 and SETDB1 in early stage of non-small cell lung cancer. Clin Transl Oncol 18: 798-804, 2016.

15. Sun QY, Ding LW, Xiao JF, Chien W, Lim SL, Hattori N, Goodglick L, Chia D, Mah V, Alavi M, et al: SETDB1 accelerates tumourigenesis by regulating the WNT signalling pathway. J Pathol 235: 559-570, 2015. 
16. Spyropoulou A, Gargalionis A, Dalagiorgou G, Adamopoulos C Papavassiliou KA, Lea RW, Piperi C and Papavassiliou AG: Role of histone lysine methyltransferases SUV39H1 and SETDB1 in gliomagenesis: Modulation of cell proliferation, migration, and colony formation. Neuromolecular Med 16: 70-82, 2014.

17. Chiba T, Saito T, Yuki K, Zen Y, Koide S, Kanogawa N, Motoyama T, Ogasawara S, Suzuki E, Ooka Y, et al: Histone lysine methyltransferase SUV39H1 is a potent target for epigenetic therapy of hepatocellular carcinoma. Int J Cancer 136: 289-298, 2015.

18. Rivière L, Gérossier L, Hantz $\mathrm{O}$ and Neuveut $\mathrm{C}$ : Hepatitis $\mathrm{B}$ virus and chromatin remodeling: $\mathrm{HBx}$ counteracts SETDB1/HP1/H3K9me3 transcriptional silencing. Med Sci 32 455-458, 2016 (In French).

19. Cicchini C, Battistelli $C$ and Tripodi M: SETDB1 is a new promising target in HCC therapy. Chin Clin Oncol 5: 73, 2016.

20. Fei Q, Shang K, Zhang J, Chuai S, Kong D, Zhou T, Fu S, Liang Y, Li C, Chen Z, et al: Histone methyltransferase SETDB1 regulates liver cancer cell growth through methylation of p53. Nat Commun 6: 8651, 2015.

21. Regina C, Compagnone M, Peschiaroli A, Lena A, Annicchiarico-Petruzzelli M, Piro MC, Melino G and Candi E: Setdb1, a novel interactor of DeltaNp63, is involved in breast tumorigenesis. Oncotarget 7: 28836-28848, 2016.

22. Zhang H, Cai K, Wang J, Wang X, Cheng K, Shi F, Jiang L, Zhang Y and Dou J: MiR-7, inhibited indirectly by LincRNA HOTAIR, directly inhibits SETDB1 and reverses the EMT of breast cancer stem cells by downregulating the STAT3 pathway. Stem Cells 32: 2858-2868, 2014.

23. Lindgren D, Sjödahl G, Lauss M, Staaf J, Chebil G, Lövgren K, Gudjonsson S, Liedberg $\mathrm{F}$, Patschan $\mathrm{O}$, Månsson W, et al: Integrated genomic and gene expression profiling identifies two major genomic circuits in urothelial carcinoma. PLoS One 7: e38863, 2012.

24. Sun Y, Wei M, Ren SC, Chen R, Xu WD, Wang FB, Lu J, Shen J, $\mathrm{Yu} \mathrm{YW}$, Hou JG, et al: Histone methyltransferase SETDB1 is required for prostate cancer cell proliferation, migration and invasion. Asian J Androl 16: 319-324, 2014.

25. Adam L, Vadlamudi RK, McCrea P and Kumar R: Tiam1 overexpression potentiates heregulin-induced lymphoid enhancer factor-1/beta -catenin nuclear signaling in breast cancer cells by modulating the intercellular stability. J Biol Chem 276: 28443-28450, 2001 .

26. Huang J, Ye X, Guan J, Chen B, Li Q, Zheng X, Liu L, Wang S, Ding Y, Ding Y and Chen L: Tiam1 is associated with hepatocellular carcinoma metastasis. Int J Cancer 132: 90-100, 2013.

27. Ooft M, van Ipenburg J, van Loo R, de Jong R, Moelans C, Braunius W, de Bree R, van Diest P, Koljenović S, Baatenburg de Jong R, et al: Molecular profile of nasopharyngeal carcinoma: Analysing tumour suppressor gene promoter hypermethylation by multiplex ligation-dependent probe amplification. J Clin Pathol 71: 351-359, 2018.

28. Roy Chattopadhyay N, Das P, Chatterjee K and Choudhuri T: Higher incidence of nasopharyngeal carcinoma in some regions in the world confers for interplay between genetic factors and external stimuli. Drug Discov Ther 11: 170-180, 2017.

29. Nakanishi Y, Wakisaka N, Kondo S, Endo K, Sugimoto H, Hatano M, Ueno T, Ishikawa K and Yoshizaki T: Progression of understanding for the role of Epstein-Barr virus and management of nasopharyngeal carcinoma. Cancer Metastasis Rev 36: 435-447, 2017

30. Ooft ML, van Ipenburg JA, Braunius WW, Zuur CI, Koljenović S and Willems SM: Prognostic role of tumor infiltrating lymphocytes in EBV positive and EBV negative nasopharyngeal carcinoma. Oral Oncol 71: 16-25, 2017.
31. Kim KY, Le QT, Yom SS, Ng RHW, Chan KCA, Bratman SV, Welch JJ, Divi RL, Petryshyn RA and Conley BA: Clinical utility of epstein-barr virus DNA testing in the treatment of nasopharyngeal carcinoma patients. Int J Radiat Oncol Biol Phys 98: 996-1001, 2017.

32. Dai J, Shen W, Wen W, Chang J, Wang T, Chen H, Jin G, Ma H, $\mathrm{Wu} \mathrm{C}, \mathrm{Li} \mathrm{L}$, et al: Estimation of heritability for nine common cancers using data from genome-wide association studies in Chinese population. Int J Cancer 140: 329-336, 2017.

33. He R, Hu Z, Wang Q, Luo W, Li J, Duan L, Zhu YS and Luo DX: The role of long non-coding RNAs in nasopharyngeal carcinoma: As systemic review. Oncotarget 8: 16075-16083, 2017.

34. Fountzilas G, Psyrri A, Giannoulatou E, Tikas I, Manousou K, Rontogianni D, Ciuleanu E, Ciuleanu T, Resiga L, Zaramboukas T, et al: Prevalent somatic BRCA1 mutations shape clinically relevant genomic patterns of nasopharyngeal carcinoma in Southeast Europe. Int J Cancer 142: 66-80, 2018.

35. Yang Y, Liu W, Zhao Z, Zhang Y, Xiao H and Luo B: Filaggrin gene polymorphism associated with Epstein-Barr virus-associated tumors in China. Virus Genes 53: 532-537, 2017.

36. Zhen Y, Fang W, Zhao M, Luo R, Liu Y, Fu Q, Chen Y, Cheng C, Zhang Y and Liu Z: miR-374a-CCND1-pPI3K/AKT-c-JUN feedback loop modulated by PDCD4 suppresses cell growth, metastasis, and sensitizes nasopharyngeal carcinoma to cisplatin. Oncogene 36: 275-285, 2017.

37. Gao H, Yu Z, Bi D, Jiang L, Cui Y, Sun J and Ma R: Akt/PKB interacts with the histone H3 methyltransferase SETDB1 and coordinates to silence gene expression. Mol Cell Biochem 305: 35-44, 2007.

38. Schultz DC, Ayyanathan K, Negorev D, Maul GG and Rauscher FJ III: SETDB1: A novel KAP-1-associated histone $\mathrm{H} 3$, lysine 9-specific methyltransferase that contributes to HP1-mediated silencing of euchromatic genes by KRAB zinc-finger proteins. Genes Dev 16: 919-932, 2002.

39. Karanth AV, Maniswami RR, Prashanth S, Govindaraj H, Padmavathy R, Jegatheesan SK, Mullangi R and Rajagopal S: Emerging role of SETDB1 as a therapeutic target. Expert Opin Ther Targets 21: 319-331, 2017.

40. Ho YJ, Lin YM, Huang YC, Chang J, Yeh KT, Lin LI, Gong Z, Tzeng TY and Lu JW: Significance of histone methyltransferase SETDB1 expression in colon adenocarcinoma. APMIS 125: 985-995, 2017.

41. Na HH, Noh HJ, Cheong HM, Kang Y and Kim KC: SETDB1 mediated FosB expression increases the cell proliferation rate during anticancer drug therapy. BMB Rep 49: 238-243, 2016.

42. Olcina MM, Leszczynska KB, Senra JM, Isa NF, Harada H and Hammond EM: H3K9me3 facilitates hypoxia-induced p53-dependent apoptosis through repression of APAK. Oncogene 35: 793-799, 2016.

43. Wong CM, Wei L, Law CT, Ho DW, Tsang FH, Au SL, Sze KM, Lee JM, Wong CC and Ng IO: Up-regulation of histone methyltransferase SETDB1 by multiple mechanisms in hepatocellular carcinoma promotes cancer metastasis. Hepatology 63: 474-487, 2016.

44. Rivière L, Gerossier L, Ducroux A, Dion S, Deng Q, Michel ML, Buendia MA, Hantz O and Neuveut C: HBx relieves chromatin-mediated transcriptional repression of hepatitis $\mathrm{B}$ viral cccDNA involving SETDB1 histone methyltransferase. J Hepatol 63: 1093-1102, 2015.

45. Thompson PJ, Dulberg V, Moon KM, Foster LJ, Chen C, Karimi MM and Lorincz MC: Correction: hnRNP K coordinates transcriptional silencing by SETDB1 in embryonic stem cells. PLoS Genet 12: e1006390, 2016. 